\title{
Una avanzadilla malograda: colonización oficial y propiedad inmueble en el protectorado español de Marruecos (1912-1956)
}

\author{
JESÚS MARCHÁN
}

\author{
PALABRAS CLAVE: protectorado español de Marruecos, coloniza- \\ ción agrícola, colonización oficial, régimen de la propiedad marro- \\ quí.
}

\section{CÓDIGOS JEL: N57, R12, R14, R30.}

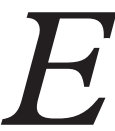

sta investigación tiene como principal objetivo el análisis del impacto de la colonización oficial -tutelada por las autoridades-en el protectorado español del norte de Marruecos (1912-1956), desde la perspectiva de la gestión y ocupación de tierras. Para llevarla a cabo, hemos utilizado fuentes referentes a la actividad agropecuaria y al derecho de propiedad en el protectorado, que se encuentran especialmente en el Archivo General de la Administración y en el boletín de leyes del protectorado. Hemos analizado la labor de los organismos agropecuarios metropolitanos que fueron implantados en el protectorado (como el Servicio Agronómico), especialmente en lo que se refiere al reparto de tierras a los colonos. Nuestro punto de partida es que el colonialismo español en Marruecos adolecía de preparación y planificación suficiente, lo cual en el futuro tendría un impacto negativo en los resultados de la actividad agropecuaria de los colonos. Alrededor del año 1900 la sociedad española tenía un conocimiento sesgado de la marroquí, cuestión que había comenzado a cambiar en la década siguiente, pero que impidió una mayor eficacia de la acción colonial. La guerra contra la resistencia rifeña y una continua falta de medios económicos contribuyeron al fracaso de esta iniciativa, con un impacto especialmente negativo entre el colonato, que en muchos casos se vio privado de la prometida ayuda oficial y logró un escaso éxito en sus explotaciones. 


\title{
A failed outpost: official colonization and properties in the Spanish Protectorate of Morocco (1912-1956)
}

\author{
KEYWORDS: Spanish protectorate of Northern Morocco, agricul- \\ tural colonization, official colonization, Moroccan property regime.
}

\author{
JEL CODES: N57, R12, R14, R30.
}

rom a perspective of land management and occupation, this article focusses on
the impact of the officially-sponsored colonization of the Spanish Protectorate
of Northern Morocco (1912-1956). Using sources in the Archivo General de la Administración and the protectorate's Bulletin of Acts and Decrees to examine farming activities and property rights, this research mainly analyzes the land distribution work of the specialized Spanish institutions that were introduced into northern Morocco. Our starting point is that Spanish colonialism in Morocco was poorly planned and insufficiently prepared, resulting in negative consequences for the agricultural efforts of the Spanish colonist farmers. Spanish society had a distorted or biased view of the Moroccan people around the year 1900, which undermined the efficacy of colonial action even though misinformation gradually diminished in the following decade. The war against the Rif resistance movement and the continuous lack of financial means contributed to the failure of this initiative. It had an especially negative impact among settlers, who were largely unsuccessful on their farms and in many cases never received the promised official support or resources

Recepción: 2016-12-22 - Revisión: 2017-11-02 • Aceptación: 2017-11-12

Jesús Marchán [orcid.org/0000-0002-2848-2633] es investigador del Grupo de Investigación en Imperios, Metrópolis y Sociedades Extraeuropeas (GRIMSE) de la Universitat Pompeu Fabra de Barcelona. Dirección para correspondencia: GRIMSE, Departament d'Humanitats, Universitat Pompeu Fabra, c/ Ramon Trias Fargas 25-27, 08005 Barcelona. Email: jesus.marchang@gmail.com 


\section{INTRODUCCIÓN}

A principios del siglo xx los gobiernos francés y español llevaron a cabo un cerco diplomático -además del económico, iniciado varias décadas antes- sobre Marruecos que culminó en 1912 con el establecimiento de un doble protectorado. A pesar de la histórica vecindad, el Imperio jerifiano era un desconocido en España y, con la excepción de la minería, el interés por el estudio de nuevas opciones de inversión y negocio había sido más bien escaso. En cuanto al comercio, tampoco tenía una posición ventajosa, pues Francia y Gran Bretaña copaban la mayor parte de las importaciones marroquíes. No parece, pues, que este tipo de motivaciones fueran decisivas a la hora de emprender este proyecto colonial. En cambio la geopolítica y la preocupación por recuperar el prestigio internacional tras el Desastre del 98 tuvieron un papel más importante (Salahdine, 1986: 34-64; Rodríguez Esteban, 1996; Pennell, 2000: 55-153; Torre, 2007; Madariaga, 2008: 133-184; 2013: 47-69; Delaunay, 2010).

A pesar del limitado interés que había despertado hasta entonces el norte de Marruecos, el desarrollo material de la zona (de unos $20.000 \mathrm{~km}^{2}$ ) era un objetivo clave del protectorado. El sector agropecuario acaparó cierta atención entre los círculos colonialistas españoles, que reactivaron la agitación a favor de intereses económicos y estratégicos en Marruecos promovidos por la Sociedad Geográfica de Madrid desde 1876. Tres décadas más tarde la explotación agrícola se convirtió en un factor de transformación para una sociedad a la que consideraban atrasada (Rodríguez Esteban, 1996; Martín, 2002a; Marchán, 2011).

Desde el siglo xix el norte de África había sido objeto de interés del Imperio francés. Su presencia dio lugar a un proceso de transformación del sector agropecuario, en el que la agricultura tradicional y la población autóctona fueron desplazadas por las explotaciones modernas de los colonos europeos. Estos a menudo trabajaban las mejores tierras gracias a la intervención de las autoridades coloniales, interesadas en la expansión de la colonización agrícola. Así, favorecieron los intereses metropolitanos y promovieron la iniciativa y la propiedad privada a partir de tierras inalienables, sin tener en cuenta las leyes inmobiliarias autóctonas. Asimismo, intervinieron en la creación de intereses económicos cuando los privados no funcionaban, como en el caso que nos ocupa, la colonización oficial dirigida por el Estado, que debía contribuir a aumentar y perpetuar la presencia metropolitana en la colonia. Esta labor fue relevante en Argelia, Túnez y el Marruecos francés. Las autoridades españolas adoptaron este sistema para la zona norte (Bouche, 1991; Aldrich, 1996). 
En Argelia, concebida como una colonia de poblamiento, las autoridades metropolitanas promovieron la llegada de europeos y organizaron la colonización mediante la desposesión de las mejores tierras a la población autóctona. En la década de 1950 los europeos (que constituían el $2 \%$ de los propietarios agrícolas) poseían más de 2,7 millones de hectáreas de las mejores tierras, de las cuales alrededor de 1 millón provenían de la colonización oficial, mientras que los argelinos poseían 7,5 (Ageron, 1979: 71-117, 480-195; Brulé \& Fontaine, 1987: 119-136; Pervillé, 2012). En Túnez, ocupada en 1881 bajo la forma del protectorado, la Administración colonial no podía llevar a cabo una política tan agresiva. El poblamiento europeo fue mucho menor, pero se emprendió un plan de colonización agrícola y de expropiación de tierras. Al final del protectorado las explotaciones de los colonos ocupaban más de 800.000 hectáreas del mejor suelo agrícola, de las cuales cerca de 200.000 habían sido entregadas por la colonización oficial (Poncet, 1962; Anderson, 1987: 151-157; Yazidi, 2005; Perkins, 2010). Finalmente en el Marruecos francés el poblamiento europeo tampoco fue prioritario. La colonización agrícola a gran escala se inició tras la destitución del primer residente general, Hubert Lyautey. Primero con una campaña para producir grandes cantidades de trigo y más tarde para fomentar el cultivo de cítricos. Al final del protectorado los colonos se habían hecho con un millón de hectáreas agrícolas, de las cuales el $25 \%$ fueron ocupadas por la colonización oficial (Bidwell, 1973: 199-221; Belguendouz, 1978; Salahdine, 1986; Swearingen, 1987; Rivet, 1999).

\section{LOS CONGRESOS AFRICANISTAS Y LA COLONIZACIÓN AGRÍCOLA}

En España el interés por el Imperio jerifiano y su desarrollo económico aumentó, como decíamos, a principios del siglo xx. En 1904 se firmó la declaración relativa a Egipto y Marruecos entre Gran Bretaña y Francia, tras la firma de la Entente Cordiale, que abrió las puertas a la extensión de la influencia gala sobre Marruecos con la participación española. En ese mismo año varios representantes de las altas esferas políticas y económicas fundaron los Centros Comerciales Hispano-Marroquíes. Su objetivo era crear una opinión favorable al desarrollo de una expansión comercial, industrial y nacional en Marruecos, con el fin de que aquel imperio constituyera un mercado de venta para los productos espanoles (Centros Comerciales Hispano-Marroquíes, 1922: 4). Tras la Conferencia de Algeciras de 1906, que dio lugar a la creación de las zonas de influencia española y francesa en el Imperio jerifiano, estas entidades organizaron los congresos africanistas para discutir las oportunidades que ofrecían las colonias africanas. En el Tercer Congreso, celebrado en Valencia en diciembre de 1909, se discutieron varios asuntos relacionados con el desarrollo agrícola. Se acordó la propuesta de apertura de granjas experimentales en las cercanías de Ceuta y Melilla para la difusión de técnicas modernas. En España ya exis- 
tían varios establecimientos de este tipo, fundados en las últimas décadas del siglo XIX para introducir los avances de la ciencia agronómica (Cartañà, 2000; Fernández Prieto, 2007). También se recomendó la creación de sindicatos de productores para enviar las cosechas a los mercados extranjeros y fomentar la iniciativa privada (Centros Comerciales Hispano-Marroquíes, 1909: 94-95). Por último, se acordó solicitar al Gobierno que tomara medidas para el acomodo de colonos españoles en territorio marroquí, con protección militar, imprescindible ante la hostilidad rifeña a la penetración extranjera en la campaña de Melilla de 1909. De hecho, la primera etapa del protectorado se prolongó hasta 1927 y se desarrolló con una parte de la población local levantada en armas contra la ocupación extranjera (Centros Comerciales Hispano-Marroquíes, 1909: 121; Madariaga, 2005: 43-71).

Unas semanas después de la celebración del Tercer Congreso Africanista, a principios de 1910, el Gobierno español comenzó a preparar el despliegue de la acción colonial. El entonces ministro de Fomento, Rafael Gasset, se desplazó a las inmediaciones de Melilla con un grupo de ingenieros civiles para evaluar el potencial económico del área oriental de la entonces zona de influencia española. Este conjunto de expertos se interesó principalmente por la minería, el principal atractivo para la inversión metropolitana (Madariaga, 2008: 133-157, 201-211; Díaz Morlán, 2015). En este grupo también viajó el ingeniero agrónomo José Vicente Arche, que estudió la situación agrícola. Al volver de Melilla presentó una breve memoria que describía una actividad agropecuaria rudimentaria, atrasada, en comparación con la española. Para promover su modernización Arche señaló la necesidad de explotar el campo rifeño con medios y técnicas innovadoras y recomendó, también, el establecimiento de una granja experimental, así como la realización urgente de un amplio estudio sobre el modo de llevar a cabo la colonización y la creación de un Servicio Agronómico en Melilla ${ }^{1}$. Gracias a este organismo se habían introducido novedades técnicas en el agro español al tiempo que se controlaba la calidad de simientes, fertilizantes y cultivos. Su papel como foco de innovación fue clave para el progreso agrícola peninsular, y se esperaba que también lo fuera en el protectorado (Pan-Montojo, 1995: 67-88; Fernández Prieto, 2007: 38-130). Este informe es el primer documento oficial conocido sobre las condiciones agrícolas del norte de Marruecos en los años previos al establecimiento del protectorado, y punto de partida para transformar la agricultura y extender la colonización agrícola. Unos pocos días más tarde, por Real Orden de 21 de enero de 1910, se aprobó el establecimiento de una granja en Nador, cerca de Melilla ${ }^{2}$.

1. «Condiciones agrícolas de nuestras posesiones del Rif», El Progreso Agrícola y Pecuario, 15/02/1910; ARCHE (1910).

2. Por motivos de seguridad, el establecimiento fue instalado en la plaza de soberanía española. «Real Orden creando en Nador una Granja Escuela Experimental», El Progreso Agrícola y Pecuario, 
Finalmente, en el Cuarto Congreso Africanista, que tuvo lugar en Madrid en diciembre de 1910, se determinó la necesidad de estudiar el régimen de propiedad autóctono y el clima, suelo y subsuelo del Rif, y la conveniencia de hacer un catastro de los terrenos ocupados, como igualmente de los adquiridos, al objeto de saber cuáles son los disponibles para un principio de colonización española (Centros Comerciales Hispano-Marroquíes, 1910: 130). Hasta entonces el derecho marroquí había despertado escaso interés en la península Ibérica ${ }^{3}$. Gracias al estrechamiento del cerco colonial aumentó, y sería una herramienta de dominio durante el protectorado. Por otra parte, tras la Conferencia de Algeciras no fueron pocas las empresas y particulares europeos que se lanzaron a la compra de tierras y a la especulación, aunque no siempre con garantías legales (Marchán, 2014: 139; Domínguez Rodríguez, 2017: 119).

Los congresos africanistas abordaron cuestiones relacionadas con el desarrollo de una agricultura moderna en Marruecos. Sin embargo, la planificación de la actividad agrícola apenas estaba en un estadio inicial. El informe de Arche fue el punto de partida de la política agraria colonial. La productividad era baja, debido al atraso tecnológico.Y para subsistir ante la escasez de recursos muchos marroquíes emigraban periódicamente a Argelia para trabajar en las granjas de los colonos europeos (Vilar, 1985; El Abdellaoui \& Chikhi, 1997: 261-265; Hart, 1997: 33-34; Michel, 1997: 205-207). Dada esta situación, la principal aspiración metropolitana pasaba por una transformación del sector -y de la sociedad- para darle un enfoque capitalista, promoviendo el aumento de la productividad para colocar los excedentes en el mercado marroquí, español o internacional. La colonización agrícola, es decir, la explotación de tierras a manos extranjeras, se introdujo desde los primeros años del protectorado como estrategia de modernización, aunque al principio no existía aparentemente una idea concreta sobre la política a seguir.

\section{LOS PRIMEROS PASOS DE LA COLONIZACIÓN AGRÍCOLA}

Tras el establecimiento del protectorado se implantaron las estructuras que gestionaban el sector agropecuario en la península Ibérica, las granjas experimentales y el Servicio Agronómico. Con ello se esperaba alcanzar, primero, la suficiencia alimentaria de la zona, y más tarde, crear excedentes para su exportación. En aquellos momentos, dado que las autoridades coloniales no controlaban toda la zona, el Ejército era la más alta instancia oficial. Para las tareas civiles se crearon tres delegaciones: servicios indígenas, servicios tri-

15/02/1910; CARTAÑ̇̀ (2000); Domínguez RodRígueZ (2017: 159-160).

3. Dos de los escasos ejemplos son MiQuéLEZ (1907) y FaLgueras (1909). 
butarios, económicos y financieros, y fomento de intereses materiales. Bajo esta última se adscribieron los citados organismos (Villanova, 2004: 146-147; Marchán, 2015).

A diferencia de la colonización libre, o privada, a cuenta y riesgo de quienes la llevaban a cabo, en la oficial las autoridades ofrecían tierras y orientación técnica para promover explotaciones modernas. Una de las primeras labores fue la búsqueda de terrenos de cultivo. En la zona francesa las autoridades coloniales promovieron la ocupación de todo tipo de tierras inalienables según el derecho marroquí. En la española, como veremos, la acción oficial se limitó a aquellas que las autoridades controlaban directamente, ante el peligro de levantar más hostilidad entre la población local, que en parte estaba levantada en armas.

El derecho marroquí, de origen musulmán con componentes del derecho consuetudinario amazigh, distinguía varios tipos de propiedad. En primer lugar, existían las tierras particulares, de las cuales se podía disponer libremente. El resto eran inalienables: las comunales, ligadas a las cabilas y al mundo rural, gracias a las cuales su población podía subsistir; las tierras del Majzén, del Gobierno marroquí, que se podían enajenar solo con su consentimiento; y las del Habús, institución pía musulmana dedicada a la beneficencia y el mantenimiento del culto con los rendimientos de sus propiedades (Marchán, 2014: 8094). Teniendo en cuenta que el Gobierno español se comprometió a respetar la ley y las costumbres autóctonas (art. 1 del Convenio hispano-francés de 27 de noviembre de 1912, que estableció el protectorado), la explotación de propiedades comunales y del Habús podía comportar conflictos con la población debido a su uso, su condición inalienable y a que no estaban directamente bajo el control de las autoridades coloniales (Mateo, 2003: 231-235). El patrimonio del Majzén, cuya gestión sí lo estaba, fue incorporado a los planes de colonización. También diversas propiedades del Estado español, adquiridas al gobierno marroquí como pago de parte de la deuda contraída y que pasaron a ser propiedades particulares (Torrejón et al., 1923; Marchán, 2014: 288-289).

Los primeros pasos de la colonización agrícola se llevaron a cabo en estas últimas propiedades, que en gran parte estaban ubicadas en el triángulo formado por las ciudades de Arcila, Larache y Alcazarquivir, una de las regiones del protectorado que reunía las mejores condiciones para la agricultura (Mapas 1 y 2). Antes de ser entregadas se tuvieron que realizar trabajos de adecuación ${ }^{4}$. En marzo de 1913 el entonces coronel Gonzalo

4. Muchas de estas tierras contenían aguas estancadas y precisaban tareas de desecación, para combatir el paludismo. A pesar de las labores que se practicaron, el problema persistió hasta el final del protectorado (TORREJÓN et al., 1923: 206-213; GARCÍA FiguerAS, 1957: 42; MOLERO, 2003; MADARIAGA, 2013: 210-211, 252-255). 
Queipo de Llano, que servía en Larache, solicitó el arrendamiento de una de estas fincas para explotarla con campesinos españoles, si bien fue desestimado. Se trataba de una idea que también manejaban las autoridades, aunque aún no existía una planificación de la actividad ${ }^{5}$.

\section{MAPA 1}

\section{Regiones agrícolas importantes del norte de Marruecos}

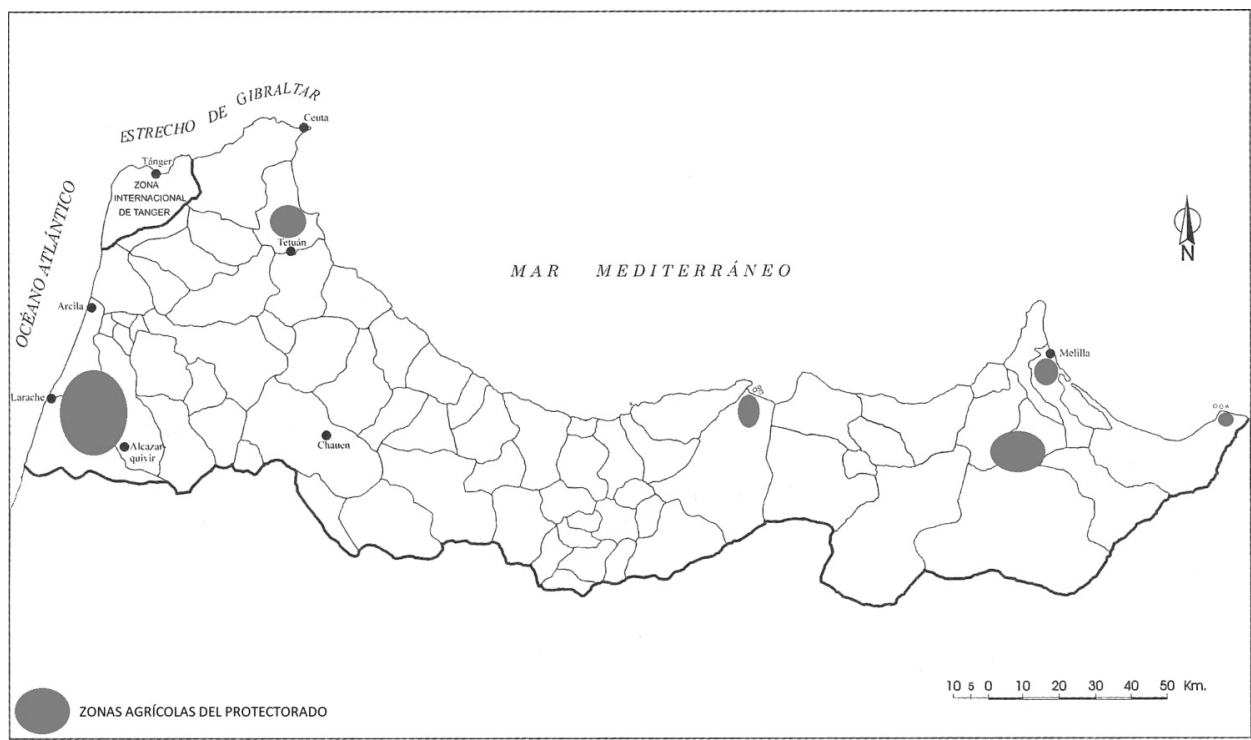

Fuente: Marchán (2014).

Dos meses después se convocó un concurso para el arrendamiento de la finca Lal-La Sfia, ubicada en la cabila de Jolot (Mapa 3). A pesar de sus grandes dimensiones (2.018 hectáreas), no se contemplaba su parcelación para repartirla entre varios beneficiarios, sino que se buscaba un solo adjudicatario. Ante la falta de interés español (en un momento en que se tenía poca información y más incerteza sobre el protectorado) el terreno fue entregado a un grupo de marroquíes. Esta decisión no fue del agrado de los círculos africanistas, ya que a su entender las tierras estaban mal trabajadas y utilizando los instrumentos agrícolas más primitivos ${ }^{6}$.

5. Archivo General de la Administración (AGA), sección África, caja 81/1419. "Alta Comisaría de España en Marruecos. Asunto: Arrendamientos. Bienes del Estado Español. Arrendamiento de fincas del estado español»; TORREJón et al. (1923: 235).

6. «El cultivo en Marruecos», África española, 1, 1913; «Lal-La Sfia y Muley Tayeb», Revista de tropas coloniales, 37, 1928; TORREJÓN et al. (1923: 234). 
MAPA 2

Orografía e hidrografía del norte de Marruecos

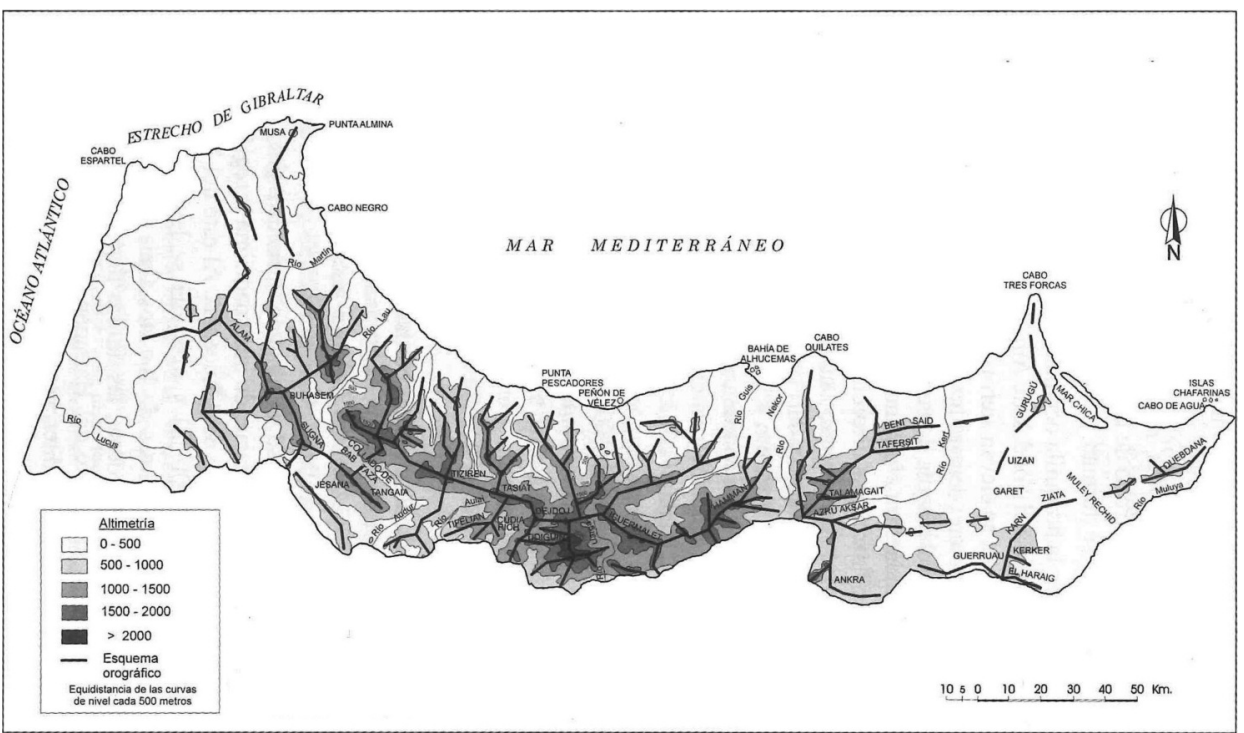

Fuente: Villanova (2003).

MAPA 3

División del territorio del protectorado por cabilas

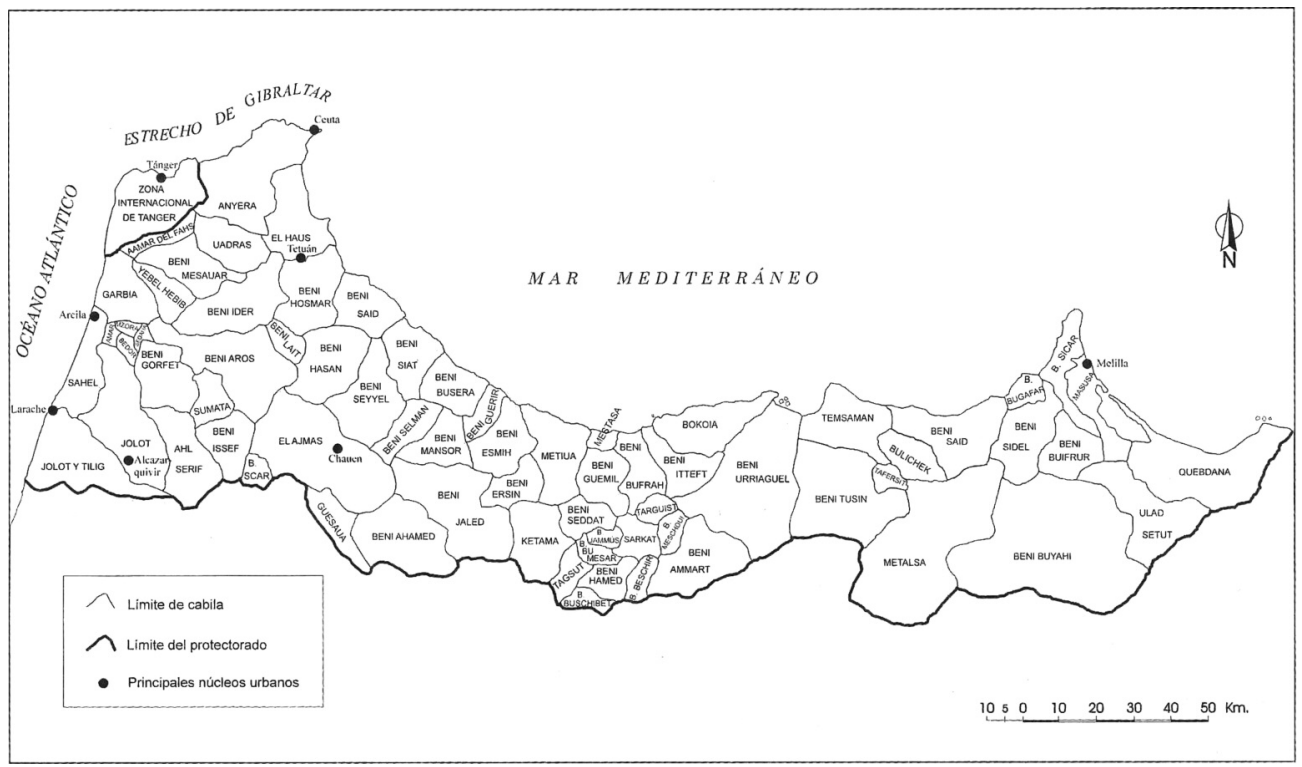

Fuente: Marchán (2014). 
Además de la redacción de un plan de colonización, también se debía regular el aprovechamiento de las propiedades del Majzén, cuya explotación correspondía al gobierno. Lo primero que se tenía que hacer era determinar su estatus jurídico dentro del nuevo marco colonial y la forma en que se podrían explotar, por lo que en 1913 se creó la Junta de Reglamentación de Bienes del Majzén ${ }^{7}$. Pero solo concluyó un trabajo, el reglamento para el arriendo de propiedades del Majzén. En materia agrícola establecía dos tipos de propiedades, según su tamaño. En primer lugar, las destinadas a pequeños cultivos, sin especificar su extensión, y cuya adjudicación era mediante subasta pública. En segundo, los terrenos para grandes cultivos, divididos en dos categorías: los que medían hasta 100 hectáreas, con un plazo de arrendamiento de entre diez y veinte años, y los que superaban esta extensión, con un plazo de entre veinte y sesenta años. En ambos casos la subasta se hacía en pliego cerrado ${ }^{8}$.

Este reglamento no regulaba el reconocimiento y catalogación de tierras ${ }^{9}$, ni su estatus jurídico, ni los concursos para su adjudicación, tampoco orientaba la colonización agrícola. Únicamente estipulaba los procedimientos que se debían seguir para obtener su arrendamiento. Lo cual no fue un impedimento para iniciar seis proyectos de explotación en este tipo de propiedades, contemporáneos al episodio de fiebre colonizadora que se vivió con anterioridad al Desastre de Annual. Los funcionarios del Registro de Inmuebles, organismo implantado por las autoridades coloniales en 1914, análogo al de la zona francesa, realizaron trabajos de reconocimiento sobre unas 49.000 hectáreas rústicas ${ }^{10}$. No fue hasta 1930 cuando se estableció de manera definitiva la condición jurídica de los bienes inmuebles. Las tierras del Majzén fueron confirmadas como inalienables, aunque

7. Boletín oficial de la zona de influencia española en Marruecos (en adelante BOZ), 25/10/1913, pp. 497-498. A partir de 1919 se pasó a llamar Boletín Oficial de la zona de Protectorado español en Marruecos.

8. BOZ, 10/06/1914, pp. 378-388.

9. Un informe previo a la promulgación del Reglamento advertía de la urgencia de llevar a cabo estas tareas: El estado de absoluto abandono en que se encuentran los bienes del Majzén y los del Habús, exigen se ponga un inmediato remedio si no se quiere que en un plazo brevísimo esos bienes desaparezcan por completo (Notas..., s. f.: 1). FALGUERAS (1909: 168) y TorREjón et al. (1923: 191) también denunciaron esta situación. Hasta 1956 se deslindaron 42.400 hectáreas de superficie agrícola del Majzén (MARCHÁN, 2014: 339-347).

10. La inscripción en el Registro de Inmuebles era facultativa. De toda la superficie deslindada, 20.000 hectáreas pertenecían a la Compañía Española de Colonización, concesionaria de tierras para colonos. El periodo 1914-1927, en especial hasta 1921, fue en el que se deslindaron más superficie y propiedades (50.247 y 341, respectivamente). Tras el fin de la campaña militar, hubo un gran descenso en las tareas de reconocimiento: en los años 1928-1939 se reconocieron 6.426 hectáreas en 192 terrenos. Durante la etapa franquista (1940-1956), el volumen de tierras reconocidas aumentó (16.606 y 1.022, respectivamente), pero no alcanzó las cifras del primer periodo (MARCHÁN, 2014: 160-229). 
se mantuvo la posibilidad de que fueran vendidas en caso de que el gobierno marroquí, bajo el control de la administración colonial española, lo autorizara (Marchán, 2014: 144$148)^{11}$.

La primera de estas fincas (Tabla 1), situada cerca de Río Martín, al noreste de Tetuán, fue adjudicada a Francisco Esgleas Nogués, un colono que poseía diversas explotaciones agrícolas en el protectorado y que se hizo cargo de 72 hectáreas. El resto lo parceló en 40 lotes (la mayoría no superaban las dos hectáreas), que subarrendó. Unos años más tarde las autoridades coloniales concedieron el derecho de adquisición de estas tierras a sus beneficiarios, considerándose de justicia social favorecer el esfuerzo material y económico realizado por los colonos subarrendatarios ${ }^{12}$. Lo mismo sucedió con los adjudicatarios de los lotes del predio Terrenos de Zeluán, de entre 6 y 26 hectáreas cada uno ${ }^{13}$.

En este periodo fueron adjudicadas cuatro fincas del Majzén más, ubicadas en la zona atlántica: Día, cuyas parcelas oscilaban entre 15 y 33 hectáreas; Dahr Mahla, con nueve lotes de menos de 15 hectáreas y 23 que medían entre 15 y 22, los cuales también fueron vendidos a sus beneficiarios en los años treinta; de Saj-Soj, propiedad de 3.885 hectáreas, se repartió una porción, con parcelas de menos de 10 hectáreas (5), de 10 a 64 (9) y de más de 100 (2); y El Adir fue arrendada a la empresa Bauer y Cía., que en 1927 cedió sus derechos de arrendamiento a la Compañía Agrícola del Lucus (CAL). Ambas eran propiedad de la casa Rotschild ${ }^{14}$.

En esta etapa se adjudicaron siete fincas más del Estado español. En 1918 el Ministerio de Estado encomendó al ingeniero agrónomo Ángel Arrué Astiazarán, director del Servicio Agronómico del protectorado, la redacción de un plan para el aprovechamiento de propiedades de este tipo situadas en la zona atlántica. Se diseñó un proyecto para estimular la llegada de pequeños capitales frente a la especulación del precio de la tierra, que había aumentado tras la Conferencia de Algeciras (Marina, 1942: 11-12). Arrué estableció un modelo de explotación que otorgaba mayor importancia a las pequeñas y medianas explotaciones y admitía la necesidad de realizar obras de saneamiento y adecuación antes de adjudicar. El perfil de colono que se buscaba era el de un agricultor

11. BOZ, 10/10/1930, pp. 1081-1089.

12. $B O Z, 10 / 09 / 1933$, pp. 813-817; «Cultivo de la remolacha en el Rif», África española, 30/11/1914; RuiZ AlbéniZ (1930: 134).

13. $B O Z, 10 / 04 / 1935$, pp. 525-529.

14. «La Compañía Agrícola del Lucus», Revista de tropas coloniales, 66, 1930; ToRREJón et al. (1923: 236-237); BOZ, 31/03/1938, pp. 169-176; LóPEZ MORELl (2005: 339-343); DoMínguEZ RoDRíGUEZ (2017: 293-300). 
español con pequeños capitales dispuesto a invertir lejos de su casa, donde las tierras tenían un precio más asequible que en la metrópoli. Así, se fomentaba la llegada de extranjeros y la modernización agrícola al tiempo que se trataba de atenuar el problema del precio de la tierra (Torrejón et al., 1923: 205-206).

\section{TABLA 1}

Colonización oficial. Reparto de tierras, 1913-1927

\begin{tabular}{lllcrrr}
\hline Nombre & Tipo de propiedad & Cabila & $\begin{array}{c}\text { Parcelas } \\
\text { ofertadas }\end{array}$ & $\begin{array}{c}\text { Extensión } \\
\text { ofertada (Ha) }\end{array}$ & $\begin{array}{r}\text { Parcelas } \\
\text { adjudicadas }\end{array}$ & $\begin{array}{r}\text { Extensión } \\
\text { adjudicada }\end{array}$ \\
\hline Lal-La Sfia & Estado español & Jolot & - & $2.018,5133$ & - & $2.018,5133$ \\
Río Martín* & Majzén & El Haus & 41 & 169,6239 & 41 & 169,6239 \\
Terrenos de Zeluán & Majzén & Beni Buifrur & 12 & 246,9500 & 12 & 246,9500 \\
Día & Majzén & Garbía & 10 & 187,4800 & 7 & 156,5770 \\
Dahar Mahla & Majzén & Sahel & 32 & 375,6715 & 27 & 323,7936 \\
Saj-Soj & Majzén & Jolot & 16 & 558,7622 & 16 & 558,7622 \\
El Adir & Majzén & Jolot & - & $2.759,8114$ & - & $2.759,8114$ \\
Huerta del Sultán & Estado español & Jolot & - & 3,5589 & - & 3,5589 \\
Huerta de Ben Auda & Estado español & Jolot & - & 2,2131 & - & 2,2131 \\
El Baitar & Estado español & Jolot & - & 4,3481 & - & 4,3481 \\
Harair & Estado español & Jolot & - & 6,2640 & - & 6,2640 \\
Tuares & Estado español & Jolot & - & 13,1028 & - & 13,1028 \\
Uelyet Bu Harek & Estado español & Jolot & - & 3,3525 & - & 3,3525 \\
Erriba & Estado español & Jolot & - & 39,3512 & - & 39,3512 \\
\hline $\mathbf{1 4}$ & & & $\mathbf{1 1 1}$ & $\mathbf{6 . 3 8 9 , 0 0 2 9}$ & $\mathbf{1 0 3}$ & $\mathbf{6 . 3 0 6 , 2 2 2 0}$ \\
\hline
\end{tabular}

*A falta de un nombre propio, hemos optado por indicar la ubicación de la finca.

Fuente: BOZ, 1913-1919; Torrejón et al. (1923); Marchán (2014: 303-309).

Para que este modelo fuera realizable, Arrué proyectó la parcelación de fincas y dispuso varias medidas que contribuyeran a una mejora de la calidad de vida de la población, tanto colonos como autóctonos. Los primeros debían realizar obras de mejora en la finca, para aumentar la superficie cultivable y la productividad. En caso de necesitar mano de obra, debían contratar preferentemente a marroquíes, consiguiendo así ventajas el arrendatario y evitación de conflictos y disgustos (Torrejón et al., 1923: 206). También se contemplaba la entrega de tierras para la población que vivía en aduares dentro de grandes fincas. Así, se promovía el desarrollo agrícola al tiempo que se creaban lazos entre españoles y marroquíes para consolidar la presencia de los primeros y de la Administración colonial. Todo ello en un momento, no lo olvidemos, en que el ejército español luchaba contra la resistencia armada rifeña y existía desconfianza entre ambas comunidades. Esta relación también establecía una jerarquía, de acuerdo con el orden colonial, en la que el 
español era el capataz y el marroquí el jornalero, concebido como inferior, desprovisto de conocimientos, capacidad de trabajo y derechos (Torrejón et al., 1923: 205-213; Marín, 2015: 93-112).

Gracias al plan de explotación de Arrué se adjudicaron siete fincas en 1919: Huerta del Sultán, Huerta de Ben Auda, El Baitar, Harair, Tuares, Uelyet Bu Harek y Erriba. Eran las que no precisaban trabajos de saneamiento. Al tratarse de contratos con un periodo de disfrute de cinco años (excepto Huerta del Sultán, de diez), tras el fin de la guerra colonial serían subastadas de nuevo (Torrejón et al., 1923: 206, 233) ${ }^{15}$. Como se puede observar en la tabla anterior, la práctica totalidad de los predios que se ofertaron, situados en su mayoría en la zona atlántica, fueron adjudicados. Se trataba de unas 6.300 hectáreas, una superficie pequeña si la comparamos con las 49.000 de fincas particulares deslindadas por los trabajadores del Registro de Inmuebles hasta 1921 (cuya práctica totalidad estaba en manos de extranjeros). Esta dinámica, y la actividad colonizadora en general, se detuvieron a partir del verano del citado año con los sucesos de Annual. La colonización oficial no se reanudó hasta que el Ejército tomó el control del territorio. El escaso despliegue inicial de la política colonial, la falta de planificación, las restricciones presupuestarias y el limitado desarrollo económico de la zona impidieron la apertura de más explotaciones. La campaña militar no hizo más que agravar estas circunstancias, desviando fondos para la «pacificación» del territorio y paralizando las tareas del campo. A pesar de estos problemas la colonización oficial había comenzado, aunque sin un plan que la orientara.

Respecto de la labor de los colonos, existen elogios oficiales. Los dahires (leyes marroquíes), que enajenaron los lotes de los primeros proyectos de colonización de tierras del Majzén, resaltaban el esfuerzo de estos pioneros. Sin embargo, no disponemos de suficiente información para valorar el trabajo del Servicio Agronómico y de los agricultores. Las parcelas ofertadas tenían superficies muy dispares, que iban de las 0,3 a las 152 hectáreas, pero abundaban las más pequeñas, de hasta 30 hectáreas. La mayoría no permitían la subsistencia de una familia por sí sola. Desconocemos si se produjeron abandonos o desahucios. La venta de parcelas de predios del Majzén fue presentada como una gratificación a los pioneros y un estímulo para atraer a más españoles en un momento, la década de 1930, en la que, como veremos, descendió la demanda de tierras. 


\section{EL PLAN DE COLONIZACIÓN DE 1923}

A pesar de que en 1921 la acción colonial se detuvo súbitamente y las tropas españolas perdieron gran parte del territorio que controlaban, no se dejó de planificar el despliegue de la labor colonizadora. En materia de agricultura las autoridades peninsulares aprobaron la extensión de las competencias de la Junta Central para la Colonización y Repoblación Interior (JCCRI) al norte de Marruecos. Gracias a este organismo, creado de la mano de la Ley de Colonización y repoblación Interior ${ }^{16}$, se abrieron colonias en la metrópoli para asentar familias que tenían un difícil acceso a la tierra en áreas despobladas o baldías. Un problema que generó tensiones sociales y éxodo rural. No fue una reforma en profundidad, pues no se realizaron cambios importantes en la estructura de la propiedad, ni se creó un grupo nuevo de pequeños propietarios. La colonización interior estaba pensada para dar tierra a familias pobres (que debían trabajar con sus medios), pero se les exigía un mínimo de capital para poner en marcha la explotación, lo cual impidió a muchos acogerse a estas concesiones y no estimuló el cambio social (Paniagua, 1992: 121-138, 364-373).

El papel que debía desempeñar la JCCRI en el protectorado era distinto, aunque guardaba algunas similitudes con las funciones que cumplía en España. Su principal cometido fue el diseño de un plan de colonización para ampliar esta actividad y proporcionar tierra y trabajo a nuevos colonos. Por Real Orden de 5 de enero de 1922 la JCCRI fue designada para elaborar un informe sobre la colonización agrícola en Marruecos para evaluar la idoneidad del territorio, especialmente la zona occidental, y la manera de llevarlo a cabo. Esta tarea fue encomendada a tres ingenieros agrónomos, Ángel de Torrejón y Boneta, Paulino Arias Juárez y Ángel Arrué Astiazarán. El nuevo plan, aprobado y publicado al año siguiente, se mantuvo vigente hasta $1956^{17}$.

En líneas generales se trataba de una ampliación del proyecto de Arrué de 1918, que coincidía con la JCCRI en su objetivo de dar acceso a la tierra a quienes lo tenían más difícil, pero con un mínimo de capital. El plan otorgaba un papel central al Servicio Agronómico: los cultivos, las técnicas empleadas, el suministro de semillas y aperos, los trabajos de mejora de las parcelas, dependían de sus orientaciones. Los pliegos de condiciones de los concursos para la adjudicación de terrenos estipulaban que lo que se hacía en las

16. Gaceta de Madrid, 08/09/1907, pp. 1009-1010.

17. «Junta Central de colonización. La colonización agrícola de Marruecos». El Progreso Agrícola y Pecuario, 22/11/1921; "La colonización en Marruecos». El Progreso Agrícola y Pecuario, 22/02/1922; «La colonización en Marruecos». El Progreso Agrícola y Pecuario, 07/08/1923; «La Junta Central de Colonización y nuestra Zona de Protectorado en Marruecos». Revista de tropas coloniales, 3 (1924); ToRREJÓN et al. (1923: 1-10). 
explotaciones debía estar en su conocimiento. La mediana y sobre todo la pequeña colonización eran la base del proyecto. Para sus autores, este modelo contribuiría al aumento de la población española en la zona gracias a la oferta de tierras a unos precios más asequibles que en la península Ibérica, y contribuiría a la difusión de técnicas de cultivo modernas. El perfil de colono que se buscaba era el de un agricultor con experiencia y un mínimo de capital para invertir en tierras y mejoras y mantener su explotación. Se ofrecerían ayudas para la obtención de semillas, aperos, el pago de la propiedad y a trabajadores ${ }^{18}$.

El plan también contemplaba, de manera excepcional, la gran colonización, llevada a cabo por grandes empresas. En este sentido priorizaba el modelo industrial agrícola, con el objetivo de obtener un alto rendimiento de las tierras y su procesamiento. La CAL, que operó en las cercanías de Larache y Alcazarquivir ${ }^{19}$, se basaba en este modelo y se convirtió en la empresa agrícola más importante del protectorado. En cambio Torrejón, Arrué y Arias no veían con buenos ojos las que se dedicaban a la concesión de tierras, pues su beneficio se basaba en la diferencia entre el precio de compra y de venta, lo cual no favorecía la productividad (Torrejón et al., 1923: 219-228, 239-260) ${ }^{20}$.

\section{LA COLONIZACIÓN OFICIAL A PARTIR DE 1927}

Vencida la resistencia armada rifeña, llegó la hora del despliegue completo de la acción colonial. El Servicio Agronómico se encargó de la adecuación de diversas propiedades de la zona atlántica, en especial en las cabilas de Jolot, Sahel y Jolot y Tilig. Al final de la década de los veinte llegaron nuevos colonos ${ }^{21}$, también para beneficiarse de la colonización oficial. En este contexto tuvo lugar una campaña propagandística de la acción española en Marruecos que ofreció una imagen positiva para el futuro del protectorado, tras años de guerra que habían dilapidado una gran cantidad de vidas y enormes sumas de dinero público. Varios propagandistas centraron su labor en enfatizar el desa-

18. Para dar apoyo económico a los colonos en 1926, se abrió el crédito agrícola en el protectorado. Como veremos más adelante los capitales de que disponía fueron insuficientes para atender sus necesidades (MARCHÁN, 2014: 177-178; DOMÍNGUEZ RODRÍGUEZ, 2017: 229-230).

19. Véase nota 14.

20. En la zona oriental del protectorado, asentada sobre tierras teóricamente privadas, operó una empresa concesionaria, la Compañía Española de Colonización. Tras el Desastre de Annual muchos de sus adjudicatarios de terrenos se arruinaron (MARCHÁN, 2014: 163-165, 184-185; DomíngUEZ RoDRíGUEZ, 2017: 181-196). Véase también nota 10.

21. El norte de Marruecos no fue un gran foco de atracción de flujos migratorios españoles. Llegó población que en gran parte procedía de Andalucía y Levante, de extracción pobre. Para evitar que dieran una mala imagen de la acción colonizadora, se establecieron medidas de entrada restrictivas (LIAUZU, 1996: 45; VILAR \& VILAR, 1999: 33-35; MARTín, 2013). 
rrollo económico de la zona y las oportunidades que ofrecía. También la colonización agrícola.

La zona atlántica fue enfatizada como la mejor región agrícola. Para el arabista Luis Antonio de Vega, estábamos ante un nuevo Orán, en alusión al desarrollo agropecuario de esta región bajo la autoridad francesa. Pero también por la comunidad procedente del Levante español, que emigró a la parte más occidental de Argelia desde la segunda mitad del siglo $\mathrm{XIX}^{22}$. Debido a su instalación previa al norte de África, según Vega, su adaptación en la zona atlántica sería muy buena y permitiría un mayor desarrollo económico. También gracias a la fertilidad de las tierras, a la seguridad y a las infraestructuras construidas para facilitar la movilidad del ejército español durante la guerra colonial ${ }^{23}$.

El ingeniero agrónomo Rafael Font de Mora, director de la granja experimental de Larache, tampoco dudaba en afirmar que esa parte del protectorado estaba llamada a revalorizarse: Existen zonas de fecundidad admirable, que exigirían minucioso estudio de las más fértiles de nuestro país para encontrar similar; tales son las vegas del [río] Lucus en Alcazarquivir y pequeñas porciones de Larache y Arcila (Font de Mora, 1928: 2).Víctor Ruiz Albéniz, destacado publicista de la presencia española en Marruecos (Nerín, 2005: 136137; Moga, 2007), lo veía de manera similar y hacía buenos presagios: El día no lejano en que se pongan en producción todas las hermosas vegas que baña el Lucus, así como las interiores de las cabilas de la región, puede darse por cierto que Alcazarquivir tendrá en justicia, sino el primero, uno de los primeros puestos, como ciudad rica y progresiva, en el Protectorado español (Ruiz Albéniz, 1930: 101-102).

A pesar de la llegada de colonos y de la consolidación del orden colonial, entre 1927 y 1936 se repartieron 17 propiedades y 2.900 hectáreas, la mitad de los repartos efectuados en el periodo anterior por la colonización oficial (Tabla 2). Se concedieron en propiedad diez fincas del Estado español ${ }^{24}$, de las cuales solo una, Handekien, fue dividida en varias parcelas (11; se adjudicaron 10), que medían entre 27 y 40 hectáreas, a excepción de dos

22. Sobre el asentamiento de españoles en el Oranesado, véanse JoRDI (1986), VILAR (1989) y MoISAND (2015).

23. «Un nuevo Orán a crear en el Garb». Revista de tropas coloniales, 33 (1927); «Temas de colonización: Lo que hallará el colono en el Garb». Revista de tropas coloniales, 35 (1927); "Corrientes de agua en El Garb». Revista de tropas coloniales, 36 (1927); «El Jolot». Revista de tropas coloniales, 39 (1928).

24. Se recibieron varias solicitudes de explotación de fincas, que el Servicio Agronómico rechazó para centrarse en el plan aprobado. AGA, sección África, caja 81/1400. "Alta Comisaría de España en Marruecos. Secretaría General. Archivo. Asunto: Régimen Inmobiliario. Inscripción en el Consulado de las propiedades inmuebles de súbditos y protegidos españoles"; AGA, sección África, caja 81/1419. "Alta Comisaría de España en Marruecos. Asunto: Arrendamientos. Bienes del Estado Español. Arrendamiento de fincas del Estado español». 
de 70 y 114. Las demás no fueron parceladas debido a su reducida extensión. Sidi Embarek, a pesar de su gran superficie, no fue dividida, fue destinada a la gran colonización. La adquirieron los empresarios Alfonso y Rafael Salvador García y sus socios marroquíes. Esta operación fue vista con buenos ojos por las autoridades coloniales, pues potenciaba una imagen de colaboración entre comunidades tras la guerra colonial ${ }^{25}$.

Como decíamos antes, buena parte de las propiedades del Majzén estaban pendientes de catalogación y existían conflictos por sus límites, pero se autorizó su explotación. Hasta el estallido de la guerra civil española se celebraron diversos concursos para la adjudicación de siete propiedades, cuya práctica totalidad estaba ubicada en la zona atlántica y cuatro fueron parceladas ${ }^{26}$. Ard-ed-Dehs, finca de gran extensión, fue explotada por la $\mathrm{CAL}^{27}$.

Tras el desembarco de Alhucemas (1925), que dio paso a la derrota de la resistencia rifeña contra el ejército colonial, en las inmediaciones del lugar los españoles fundaron Vi1la Sanjurjo. En esta área confluían las vegas de los ríos Nekkor y Guis, sobre las cuales se proyectó la colonización de más de 8.000 hectáreas. Sin embargo, el proyecto no experimentó un gran desarrollo. Tras el fin de la guerra colonial se creó una granja experimen$\mathrm{tal}^{28}$, pero la poca actividad agrícola que desarrollaron los españoles se hizo en tierras particulares. En 1926 las autoridades coloniales incautaron bienes y propiedades de Abdelkrim y sus seguidores en esa área (Madariaga, 2008: 331-332; Marchán, 2014: 373-374), donde no abundaba la propiedad del Majzén, y que debían servir para desarrollar el proyecto. Pero no fue así. Solo se ofertó, sin éxito, una finca, llamada Ein Zoren. Y el crecimiento agrícola que se esperaba no llegó, en parte debido a la reducción de la dotación presupuestaria del protectorado en los años treinta. Bien es cierto que en esos momentos Tetuán y la zona atlántica gozaban de un mayor desarrollo agropecuario y el control de las autoridades coloniales y el Ejército sobre la población era más efectivo que en el antiguo bastión

25. AGA, sección África, caja 81/1419. «Alta Comisaría de España en Marruecos. Asunto: Arrendamientos. Bienes del Estado Español. Arrendamiento de fincas del estado español»; $B O Z, 10 / 11 / 1927$, pp. 1112-1114; BOZ, 25/02/1928, pp. 196-197; BOZ, 10/08/1928, pp. 778-788; BOZ, 25/10/1928, pp. 968-970. Una parte de Sidi Embarek fue asignada a la población de un aduar.

26. El tamaño de los lotes oscilaba: La Guedira, 20-37 hectáreas; Huertas de Larache, 0-5 hectáreas, salvo dos de 9 y 10; Tzendaffel, cuatro parcelas de 85-117 hectáreas y diez más de entre 4 y 11 . Respecto de Saj-Soj, Rafael Font de Mora se hizo con la explotación de un lote de 46 hectáreas. $B O Z$, 10/03/1928, pp. 252-274; BOZ, 25/06/1928, pp. 669-670; BOZ, 10/09/1930, pp. 960-968; BOZ, 10/06/1931, pp. 655-664; BOZ, 10/05/1934, pp. 288-294.

27. BOZ, 10/07/1929, pp. 628-634; «La Compañía Agrícola del Lucus». Revista de tropas coloniales, 66, junio de 1930.

28. AGA, sección África, caja 81/647. «Inspección sección $1^{\mathrm{a}}, 2^{\mathrm{a}}$ sección, $3^{\mathrm{a}}$ división. Informaciones», 1933. 
rifeño. Ahora bien, lo que bloqueó el avance de este proyecto fue el descubrimiento de la alta salinidad del río Nekkor, que impedía una mayor productividad y lo descartaba definitivamente (Ruiz Albéniz, 1930: 107-111; Torrejón et al., 1939: 14-15; García Figueras, 1957: 36; Fleming, 1998; Madariaga, 2008: 332; Martín, 2008).

En este periodo se emprendió otro proyecto oficial, los perímetros de colonización. Se trataba de un modelo de explotación utilizado en la zona francesa: grandes extensiones de terrenos agrícolas en las que se mezclaban propiedades particulares e inalienables y cuya explotación estaba orientada por el Servicio Agronómico. Mientras que en la zona gala las autoridades forzaron la explotación de tierras comunales y del Habús, en la española se limitaron al uso de particulares y del Majzén ${ }^{29}$. Diversas fincas de este tipo formaban parte de estos recintos, como Llanos del Martín, Tzendaffel, Kudia Fraicatz, SajSoj, Zem Zem o Tzelata de Reisana. En 1930 se iniciaron los trabajos de reconocimiento $\mathrm{y}$ adecuación de varios perímetros, pero no fueron suficientes para que todos entraran en funcionamiento. Con el fin de hacer una gestión eficaz se sopesó la posibilidad de incautar las tierras particulares, para asegurar que se siguieran las directrices oficiales. Pero las autoridades priorizaron la conservación de la paz social. Dadas estas dificultades, a finales de los años treinta se dejaron de crear perímetros, de manera que las tierras cultivadas según las orientaciones oficiales eran las que se habían adjudicado por concurso (Marchán, 2014: 352-357; Domínguez Rodríguez, 2017: 249-261).

A la vista de los resultados de la Tabla 2, en esta etapa el avance de la colonización oficial fue menor que en la anterior. Lo cual llamó la atención de la Delegación de Asuntos Indígenas (DAI) ${ }^{30}$. A principios de 1935 su máximo responsable, el coronel Fernando Capaz, mostró su preocupación por la gestión de los predios agrícolas del Majzén al secretario general, número dos en la jerarquía de la Alta Comisaría, debido a que varios permanecían baldíos. Capaz señalaba como responsables a la Delegación de Fomento y al Servicio Agronómico, y ofrecía como solución la gestión de la DAI ${ }^{31}$. El jefe del Servicio Agronómico, Ángel de Torrejón y Montero (hijo de Torrejón y Boneta), negó tales pro-

29. $B O Z, 25 / 07 / 1929$, pp. 688-692; BOZ, 10/10/1929, pp. 1056-1059; SwEARINGEN (1987). El uso del patrimonio comunal no solo dependía del citado recelo que podían suscitar entre los marroquíes. La Alta Comisaría realizó un estudio sobre el patrimonio comunal de ocho cabilas de la región de Tetuán que abarcaba más de 9.000 hectáreas. 1.000 eran de uso agrícola, y precisaban ingentes trabajos de acondicionamiento. AGA, sección África, caja 81/1416. «Catalogación provisional de bienes de las yemáas de algunas cabilas de la región de Yebala».

30. Este organismo se ocupaba de la gestión de gran parte de las cuestiones que implicaban un contacto directo y asiduo con la población marroquí (VILlanova, 2004).

31. AGA, sección África, caja 81/1306. «Secretaría General. Asesoría jurídica. Carta del Delegado de Asuntos Indígenas al Secretario General», 07/01/1935. 
blemas $^{32}$. Pero unos meses más tarde se promulgó una reforma del reglamento para la catalogación y deslinde de los bienes Majzén y de las colectividades indígenas, de 1929, que otorgó a la DAI las competencias reclamadas por Capaz y relegó al Servicio Agronómico a una función asesora ${ }^{33}$.

TABLA 2

Colonización oficial. Reparto de tierras 1927-1936

\begin{tabular}{lllrrrr}
\hline Nombre & Tipo de propiedad & Cabila & $\begin{array}{c}\text { Parcelas } \\
\text { ofertadas }\end{array}$ & $\begin{array}{r}\text { Extensión } \\
\text { ofertada (Ha) }\end{array}$ & $\begin{array}{r}\text { Parcelas } \\
\text { adjudicadas }\end{array}$ & $\begin{array}{r}\text { Extensión } \\
\text { adjudicada }\end{array}$ \\
\hline Handekien & Estado español & Sahel & 11 & 472,2950 & 10 & 440,0575 \\
Huerta del Sultán & Estado español & Jolot & - & 3,5589 & - & 3,5589 \\
Huerta de Ben Auda & Estado español & Jolot & - & 2,2131 & - & 2,2131 \\
El Baitar & Estado español & Jolot & - & 4,3481 & - & 4,3481 \\
Harair & Estado español & Jolot & - & 6,2640 & - & 6,2640 \\
Tuares & Estado español & Jolot & - & 13,1028 & - & 13,1028 \\
Erriba & Estado español & Jolot & - & 39,3512 & - & 39,3512 \\
Uelyet Bu Haret & Estado español & Jolot & - & 3,3525 & - & 0,0000 \\
Masmudi & Estado español & Jolot & - & 5,5078 & - & 5,5078 \\
La Guedira & Majzén & Jolot & 26 & 715,3500 & 26 & 639,4700 \\
Huertas de Larache & Majzén & Jolot y Tilig & 11 & 35,7346 & 10 & 35,0196 \\
Sidi Embarek & Estado español & Jolot y Tilig & - & 637,3969 & - & 637,3969 \\
Ard-ed-Dehs & Majzén & Jolot & - & 576,7126 & - & 576,7126 \\
Ein Zoren & Majzén & Beni Urriaguel & - & 12,4288 & - & 0,0000 \\
Tzendaffel & Majzén & Sahel & 14 & 483,5814 & 10 & 462,6948 \\
Kediuat el Hamara & Majzén & El Haus & - & 70,3370 & - & 0,0000 \\
Saj-Soj & Majzén & Jolot & 1 & 45,9321 & 1 & 45,9321 \\
\hline $\mathbf{1 7}$ & & & $\mathbf{6 3}$ & $\mathbf{3 . 1 2 7 , 4 6 6 8}$ & $\mathbf{5 7}$ & $\mathbf{2 . 9 1 1 , 6 2 9 4}$ \\
\hline
\end{tabular}

Fuentes: elaboración propia a partir de decretos visiriales y dahires publicados en el $B O Z$; Torrejón et al. (1923); Marchán (2014: 262-271, 361-383).

Este cambio se enmarca en un periodo en que el poder militar pugnó por mantener el control de las estructuras del protectorado. El primer gobierno de la Segunda República española fomentó una Administración con un carácter más civil, tras años de dominio mi-

32. AGA, sección África, caja 81/1306. «Secretaría General. Asesoría jurídica. Sobre aprovechamiento agrícola de los bienes Majzén, catalogados y deslindados. Carta del Jefe del Servicio Agronómico a la Delegación de Fomento", 21/03/1935. Según la prensa del momento, se disponía de 6.400 hectáreas pendientes de adjudicar. "La obra agrícola del protectorado español en Marruecos», $A B C$, 06/04/1935.

33. BOZ, 31/08/1935, pp. 1061-1070; AGA, sección África, caja 81/1306. «Secretaría General. Asesoría jurídica. Sobre aprovechamiento agrícola de los bienes Majzén, catalogados y deslindados. Carta de la Secretaría General a la Alta Comisaría", 19/08/1935. En esta misiva se hace referencia a otra anterior en la que ambas partes acuerdan estos cambios (MARCHÁN, 2014: 325-327). 
litar. Capaz, que estaba en contra de este giro, dimitió como delegado de Asuntos Indígenas. Pero gracias al ascenso del gobierno conservador fue restituido en el cargo. Desde allí hizo presión para que los militares recuperaran el control de la Administración colonial. En el caso expuesto consiguieron nuevas atribuciones en detrimento de expertos civiles (Villanova, 2004: 177-186; Villanova, 2006: 48-54).

Ahora bien, no podemos atribuir únicamente a los organismos técnicos el menor avance de la colonización oficial. La mayor parte de las tierras adjudicadas en este periodo fueron entregadas hasta principios de los años treinta. La crisis financiera internacional, que también afectó al protectorado, contribuyó a frenar la demanda. Cabe preguntarse, pues, si era necesario convocar más concursos o bien parcelar más fincas para hacerlas más accesibles a los pequeños capitales. En este periodo solo se dividieron cuatro, con 20 lotes que medían de 0 a 11 hectáreas, y 37, de 20 a 40.

Buena parte de los colonos que se acogieron a la colonización oficial sufrieron serias dificultades para mantener sus explotaciones. Diversos agricultores tuvieron que abandonarlas porque no podían afrontar sus deudas, ya fuera por el impago de cuotas o por la falta de capitales para sufragar gastos. Es el caso de varios adjudicatarios de las fincas La Guedira, Huertas de Larache y Handekien. En esta última un grupo se plantó en bloque. En octubre de 1935 el Sindicato Agrícola de Arcila emitió un comunicado en el que anunciaba el abandono de varios lotes. Los colonos se sentían perjudicados por la política comercial de puertas abiertas del protectorado, que fue acordada en la Conferencia de Algeciras y ratificada en el convenio del protectorado de 1912. La competencia de los productos agrícolas de la zona francesa les perjudicaba. Otro problema que les afectaba era la obtención de liquidez para las inversiones en las obras de regadío que estaban obligados a realizar. El crédito agrícola no cubría sus necesidades y la banca no ofrecía soluciones: al no disponer del título de propiedad de sus parcelas (eran arrendatarios) no disponían de un aval para obtener un crédito, y solo podían recurrir a prestamistas. Así, solicitaron a las autoridades que designaran nuevos adjudicatarios y que les reintegraran el capital invertido. El entonces alto comisario Manuel Rico Avello, que era conocedor de estos problemas, no emprendió acciones para ayudar a los colonos, o bien no disponía de medios económicos para hacerlo. La prensa peninsular denunció esta pasividad, tachándola de fracaso de la política colonial, al tiempo que elogiaba el esfuerzo de los colonos. En marzo de 1936, con la llegada del nuevo alto comisario, Juan Moles, nada cambió. Varias semanas después el estallido de la guerra civil lo pospuso sine die ${ }^{34}$.

34. «La obra agrícola del protectorado español en Marruecos», $A B C, 06 / 04 / 1935$; «Una grave decisión en Marruecos», $A B C, 17 / 10 / 1935$; "Colonización», $A B C, 23 / 10 / 1935$; «La economía de nuestro protectorado marroquí", El Popular, 04/01/1936; GozÁlvez PÉREZ (1993-1994: 436-437); MADA- 


\section{LA ETAPA FRANQUISTA}

La contienda metropolitana dejó la labor colonial en un segundo término. El levantamiento contra la Segunda República triunfó rápidamente en las plazas de soberanía española en el norte de África y el protectorado, y fue seguido de una brutal represión contra quienes fueron considerados desafectos a la causa de los sublevados. Se realizaron detenciones, ejecuciones, castigos y venganzas sobre más de cinco mil españoles (Martín, 2002b: 118-119; Nerín, 2005: 165-222; Madariaga, 2013: 257-282). Los colonos también se vieron envueltos en esta espiral de persecución y ajusticiamiento arbitrario, que propició el abandono o cambio de concesionarios en diversos predios. Para las nuevas autoridades se trataba de un incumplimiento de contrato o impago de cuotas. Pero lo cierto es que estos argumentos no concuerdan con las condiciones de las concesiones y hay varios nombres de colonos que aparecen en listas de represaliados. Ni siquiera se libraron quienes habían desarrollado una dilatada labor en la zona, como Rafael Font de Mora, investigado por desafección al Movimiento, y a quien se le arrebataron sus tierras y las que arrendaba ${ }^{35}$.

Otro problema igualmente grave fue la carestía de alimentos que sufrió el Rif desde 1936, que se prolongó durante los años cuarenta. Muchas familias abandonaron el campo y fueron a las ciudades, o bien emigraron a la zona francesa, sin que las autoridades españolas pusieran impedimentos. Treinta años después del establecimiento del protectorado, uno de sus principales objetivos, la suficiencia alimentaria, no se había alcanzado. La Administración colonial emprendió varias acciones para paliar los efectos de la hambruna, pero difícilmente lo podía hacer de manera inmediata. Se entregaron tierras a poblados; se puso en marcha un plan de obras hidráulicas para aumentar los regadíos, abastecer de agua a diversas poblaciones y producir electricidad; se trató de estimular el arrendamiento de tierras incultas sancionando a sus propietarios; y se concedieron primas para aumentar la productividad. Para este sector, el problema central era económico. La agricultura tradicional no podía alimentar a toda la población; muchos colonos tenían serias dificultades para mantener sus explotaciones e introducir las mejoras exigidas. Y poco podían contar con la ayuda oficial ${ }^{36}$.

RIAGA (2013: 206-216, 244-248).

35. AGA, sección África, caja 81/1348. «Reclamo de devolución de terrenos por desafección al Movimiento por parte de Rafael Font de Mora». Solo unos años antes, Víctor Ruiz Albéniz, muy cercano a los militares franquistas, lo consideraba uno de los colonos más destacados del protectorado (1930: 134). Para los demás colonos represaliados, véase Marchán (2014: 364-366, 370-371).

36. Morla (1947: 94); AzIZA (2003: 177-185, 191-193); Domínguez RodríGuez (2017: 288). Esta coyuntura fue aprovechada por especuladores para comprar tierras a campesinos empobrecidos a precios irrisorios. Las autoridades coloniales prohibieron las ventas en el Rif central que dejaran a los 
Tras el fin de la guerra civil, se reanudó el reparto de tierras bajo la supervisión de la DAI. El avance de la colonización fue de nuevo menor. De las 16 fincas que salieron a concurso se adjudicaron siete, que sumaban 790 hectáreas (Tabla 3). Las autoridades no solo hicieron parcelas de pequeño tamaño. Gran parte de Kudia Fraicatz (de 442 hectáreas en total) fue dividida en dos de 229 y 95 ; se acondicionaron dos lotes más en ZemZem, de 38 y 10 hectáreas; y Lagunas de Azarak fue dividida en tres trozos de 65, 62 y 20 hectáreas (Marchán, 2014: 379, 384-388).

Tzelata de Reisana devino el gran proyecto agrícola del periodo franquista: una colonia compartida por campesinos marroquíes y españoles. Se trataba de una finca originariamente del Majzén de la cual el Estado español adquirió una parte. La actividad en el predio comenzó en los años veinte, como campo de demostración. En la década siguiente se emprendió un proyecto de perímetro de colonización, albergó una oficina de propaganda agrícola y se planificó la apertura de una estación general de agricultura, dependencias de las intervenciones y una escuela. Ante la falta de continuidad de estos planes, en los años cuarenta los esfuerzos oficiales se centraron en la apertura de campos de cultivo. De la parte del Majzén, en 1944 se entregaron 17 lotes (de 29) en régimen de arrendamiento con opción de compra. Cada uno medía entre 15 y 20 hectáreas. La parte del Estado español salió a concurso dos años más tarde. Pero no hubo más adjudicaciones, a pesar de que se celebraron tres convocatorias más. Si bien desconocemos la superficie exacta adjudicada, el hecho de que se entregaran menos de la mitad de las parcelas ofertadas da cuenta del escaso impacto de este proyecto ${ }^{37}$.

En esta etapa la colonización oficial arrastró los problemas de las anteriores. La llegada de colonos fue menor debido al endurecimiento del control de la población y de las condiciones de entrada. También por los problemas económicos de quienes podían plantearse su traslado al protectorado, en un periodo de delicada situación financiera española. La mayor parte de las parcelas que se entregaron eran de pequeño tamaño (15-20 hectáreas), mientras que de las que se quedaron sin adjudicar siete medían más de cincuenta hectáreas. Gran parte de las fincas ofertadas precisaban tareas de desecación y una fuerte inversión. Si los problemas económicos fueron muy graves en los años cuarenta, en la siguiente década la inestabilidad política del norte de África y la amenaza que suponía la descolonización para los negocios metropolitanos no garantizaba la recuperación de la in-

vendedores con menos de dos hectáreas de regadío u ocho de secano, consideradas como necesarias para asegurar la subsistencia. AGA, sección África, caja 81/1321. "Alta Comisaría de España en Marruecos. Delegación General. Expediente núm. L-1. Reforma del Dahir de 8 de marzo de 1946 sobre la venta de terrenos en el Kert»; Villanova (2004: 104-105).

37. «La obra agrícola del protectorado español en Marruecos», $A B C, 06 / 04 / 1935$; BRAVo (2000: 119); Aziza (2003); MARChÁN (2014: 271-276, 385-386); Domínguez RodRíGueZ (2017: 354-356). 
versión. En general, tanto colonos como población autóctona siguieron pasando penurias. Las ayudas destinadas a la colonización oficial siguieron sin cubrir las necesidades de los colonos. De manera que los problemas económicos que se habían puesto sobre la mesa en los años treinta no cesaron ${ }^{38}$.

TABLA 3

Colonización oficial. Reparto de tierras, 1940-1956

\begin{tabular}{|c|c|c|c|c|c|c|}
\hline Nombre & Tipo de propiedad & Cabila & $\begin{array}{l}\text { Parcelas } \\
\text { ofertadas }\end{array}$ & $\begin{array}{c}\text { Extensión } \\
\text { ofertada }(\mathrm{Ha})\end{array}$ & $\begin{array}{c}\text { Parcelas } \\
\text { adjudicadas }\end{array}$ & $\begin{array}{l}\text { Extensión } \\
\text { adjudicada }\end{array}$ \\
\hline Kediuat el Hamara & Majzén & El Haus & - & 70,3370 & - & 70,3370 \\
\hline Tzelata de Reisana* & $\begin{array}{l}\text { Majzén } \\
\text { y Estado español }\end{array}$ & Jolot & $29+?$ & $507,5000+?$ & 17 & $297,5000+?$ \\
\hline Thilfau & Majzén & El Ajmás & - & 12,2800 & - & 12,2800 \\
\hline Tagasut y Suilha & Majzén & El Ajmas & - & 6,3600 & - & 0,0000 \\
\hline El Guedalia & Majzén & Ahl Serif & - & 62,9475 & - & 0,0000 \\
\hline Kudia Tuirsa & Majzén & Garbía & 2 & 207,2050 & 0 & 0,0000 \\
\hline Bumsaham & Majzén & Guesaua & 3 & 57,2840 & 0 & 0,0000 \\
\hline Kudia Fraicatz & Majzén & Bedor & 2 & 324,8289 & 1 & 229,2064 \\
\hline Zem-Zem & Majzén & El Haus & 2 & 47,7544 & 1 & 9,8394 \\
\hline Saj-Soj & Majzén & Jolot & 3 & 272,3800 & 0 & 0,0000 \\
\hline Olivar del zoco de & Majzén & Beni Bugafar & - & 5,3070 & - & 0,0000 \\
\hline \multicolumn{7}{|l|}{ Telata de Beni Bugafar } \\
\hline La Albina & Majzén & El Haus & 1 & 20,2186 & 0 & 0,0000 \\
\hline Muliha & Majzén & El Haus & 1 & 30,7360 & 0 & 0,0000 \\
\hline Merya Zarafa & Estado español & Jolot & - & 203,7200 & - & 0,0000 \\
\hline Lagunas de Azarak & Majzén & Jolot & 3 & 147,9400 & 3 & 147,9400 \\
\hline Menasel y Krota & Majzén & Sahel & 1 & 22,8364 & 1 & 22,8364 \\
\hline 16 & & & $47+?$ & $1.999,6348+?$ & 23 & $789,9392+?$ \\
\hline
\end{tabular}

^La cifra de extensión ofertada para esta propiedad es aproximada. Al no especificarse los datos sobre un segundo concurso que se realizó, hemos añadido un interrogante. Lógicamente tampoco es posible ofrecer la superficie exacta adjudicada.

Fuente: elaboración propia a partir de dahires, decretos visiriales y anuncios publicados en el $B O Z$.

38. AGA, sección África, caja 81/1328. «Alta Comisaría de España en Marruecos. Secretaría General. Expediente núm. 524. Asunto: Telata de Reixana», 1944; «El teniente general García Valiño visita las cabilas de Jolot y Sahel", $A B C, 06 / 07 / 1955$; MADARIAGA (2013: 243, 408-456); MARCHÁN (2014: 275, 380-389); DOMÍNGUEZ RODRÍGUEZ (2017: 327-331). 


\section{CIFRAS GLOBALES}

A la luz de lo expuesto, la colonización oficial adjudicó 10.000 hectáreas agrícolas en un periodo de 44 años (Tabla 4). La mayor parte de esta superficie se comenzó a explotar en la primera etapa (correspondiente a la guerra colonial), paradójicamente cuando no existía un plan de colonización. Posteriormente el avance de suelo colonizado fue menor. La gran colonización, con un carácter teóricamente excepcional, representó la mayor parte de las tierras entregadas, alrededor de seis mil hectáreas. La CAL, como gran empresa agropecuaria, acaparó buena parte de esta superficie.

\section{TABLA 4}

Colonización oficial. Fincas adjudicadas, 1913-1956

\begin{tabular}{lrrrrrr}
\hline Periodo & $\begin{array}{c}\text { Fincas y parcelas } \\
\text { ofertadas }\end{array}$ & Extensión ofertada (Ha) & $\begin{array}{c}\text { Fincas y parcelas } \\
\text { adjudicadas }\end{array}$ & $\begin{array}{r}\text { Extensión } \\
\text { adjudicada (Ha) }\end{array}$ \\
\hline $1913-1927$ & 14 & 111 & $6.389,0029$ & 14 & 103 & $6.306,2220$ \\
$1928-1936$ & 17 & 63 & $3.127,4668$ & 14 & 57 & $2.911,6294$ \\
$1940-1956$ & 16 & $47+?$ & $1.999,6348+?$ & 7 & 23 & $789,9392+?$ \\
\hline TOTAL & $\mathbf{4 7}$ & $\mathbf{2 2 1 + ?}$ & $\mathbf{1 1 . 5 1 6 , 1 0 4 5 + ?}$ & $\mathbf{3 5}$ & $\mathbf{1 8 3}$ & $\mathbf{1 0 . 0 0 7 , 7 9 0 6 + ?}$ \\
\hline
\end{tabular}

Fuente: tablas 1-3 del presente trabajo.

TABLA 5

Colonización oficial por cabilas, 1913-1956

\begin{tabular}{lrrrrrr}
\hline Periodo & $\begin{array}{c}\text { Fincas y parcelas } \\
\text { ofertadas }\end{array}$ & Extensión ofertada (Ha) & $\begin{array}{c}\text { Fincas y parcelas } \\
\text { adjudicadas }\end{array}$ & $\begin{array}{r}\text { Extensión } \\
\text { adjudicada (Ha) }\end{array}$ \\
\hline El Haus & 6 & 45 & 409,0069 & 3 & 42 & 249,8003 \\
El Ajmas & 2 & - & 18,6400 & 1 & - & 12,2800 \\
Guesaua & 1 & 3 & 57,2840 & 0 & - & 0,0000 \\
Jolot & 25 & $78+?$ & $7.956,5106+?$ & 22 & 63 & $7.191,1781+?$ \\
Garbía & 2 & 12 & 394,6850 & 1 & 7 & 156,5770 \\
Sahel & 4 & 58 & $1.354,3843$ & 3 & 48 & $1.249,3823$ \\
Jolot y Tilig & 2 & 11 & 673,1315 & 2 & 10 & 672,4165 \\
Ahl Serif & 1 & - & 62,9475 & 0 & - & 0,0000 \\
Bedor & 1 & 2 & 324,8289 & 1 & 1 & 229,2064 \\
Beni Buifrur & 1 & 12 & 246,9500 & 1 & 12 & 246,9500 \\
Beni Urriaguel & 1 & - & 12,4288 & 0 & - & 0,0000 \\
Beni Bugafar & 1 & - & 5,3070 & 1 & - & 0,0000 \\
\hline TOTAL & $\mathbf{4 7}$ & $\mathbf{2 2 1 + ?}$ & $\mathbf{1 1 . 5 1 6 , 1 0 4 5 + ?}$ & $\mathbf{3 5}$ & $\mathbf{1 8 3}$ & $\mathbf{1 0 . 0 0 7 , 7 9 0 6 + ?}$ \\
\hline
\end{tabular}

Fuente: elaboración propia a partir de las tablas 1-4 del presente trabajo. 


\section{MAPA 4}

\section{Distribución por cabilas de la superficie adjudicada para la colonización oficial (1916-1956)}

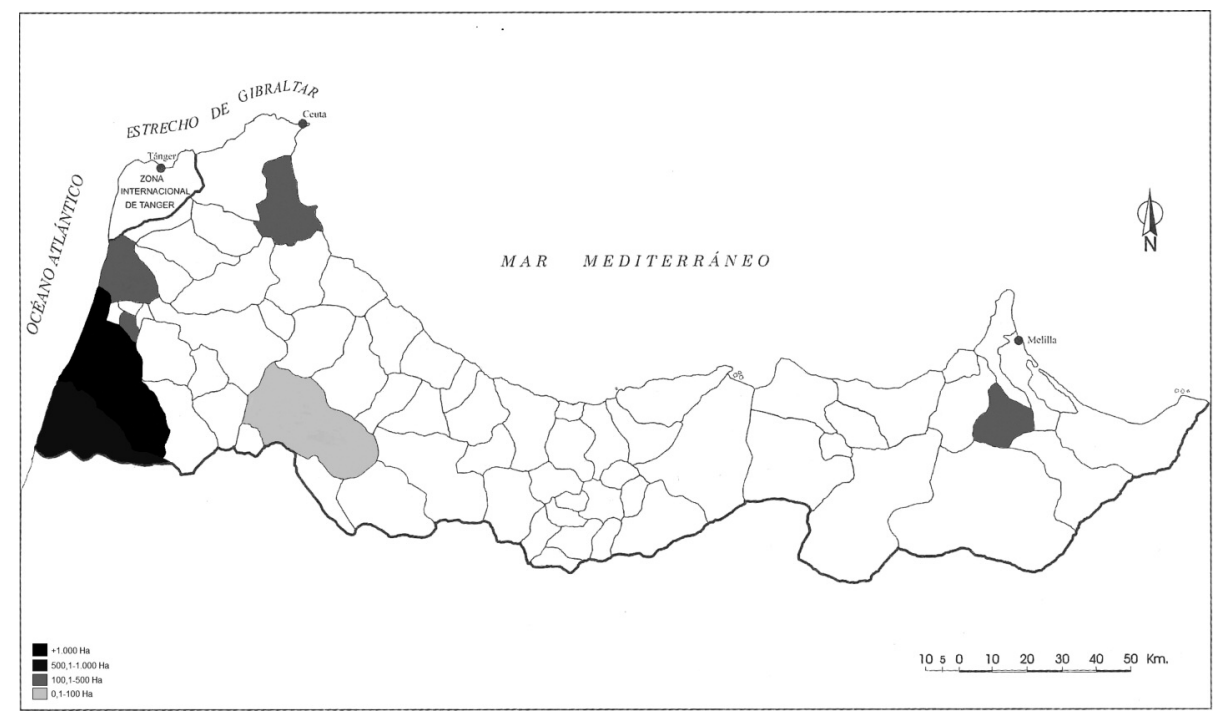

Fuente: elaborado a partir de la tabla 5 del presente trabajo.

La derrota de Annual marcó un antes y un después en la vida del protectorado. Hasta 1921 la colonización privada experimentó un primer avance. La oficial, sin una planificación formal de la actividad, repartió una cantidad mucho menor, pero ofrecía buenas perspectivas de cara al futuro, una vez la resistencia armada rifeña fuera derrotada. Sin embargo, los citados sucesos destruyeron buena parte de la labor colonial hecha hasta entonces, que quedó frenada. Unos pocos años más tarde, tras la derrota de la resistencia armada rifeña y la aprobación del plan de colonización, se reanudaron las adjudicaciones de tierras. Pero en los años treinta los problemas financieros españoles, derivados de la gran recesión internacional, que se extendieron al protectorado, mermaron la actividad, a la que se le dedicaron menos recursos. La demanda de tierras cayó, lo que redujo el avance de la colonización oficial respecto del primer periodo. Estos problemas persistieron en la etapa franquista, en la que gran parte de la población del protectorado vivió momentos de penuria, e incluso se agravaron, pues la progresión fue menor que en el anterior periodo.

En cuanto a la distribución geográfica, la mayor parte de la superficie estaba localizada en la zona atlántica (más del 90\%), especialmente en las cabilas de Jolot, Sahel y Jolot y Tilig (Tabla 5; Mapa 4), que reunían las mejores condiciones agrícolas del protectorado, en especial la cuenca del río Lucus. Los otros dos ámbitos sumaban juntos 500 
hectáreas. El primero era la vega de Tetuán, en la cabila de El Haus, donde se inició el primer ensayo de reparto de parcelas. Debido a su condición de capital era un lugar más seguro para los colonos. Sin embargo, la colonización privada tuvo más impacto que la oficial, con 1.760 hectáreas adquiridas por extranjeros. El segundo estaba en la región oriental, en Beni Buifrur, cerca de Nador y Melilla. Contaba con una considerable presencia española debido a la actividad minera, pero no reunía unas condiciones agrícolas tan buenas como la zona occidental. La parcelación de una finca del Majzén en la primera etapa, junto a la instalación de colonos por su propia cuenta y de la Compañía Española de Colonización propiciaron una auténtica fiebre colonizadora, con la adquisición de más de treinta mil hectáreas agrícolas privadas. El impacto de la derrota de Annual redujo la actividad colonizadora a la privada (que también se vio seriamente afectada) y no se emprendió ningún proyecto más de cierta importancia, a excepción del de la vega de Alhucemas, que no prosperó (Marchán, 2014: 229-233).

\section{CONSIDERACIONES FINALES}

La colonización oficial tenía como objetivo principal la modernización agropecuaria, así como garantizar la presencia española en suelo marroquí. Este proceso debía transformar el sector -y la sociedad- para conseguir la suficiencia alimentaria, y más adelante crear y vender excedentes en los mercados nacional e internacional. Unos propósitos que no se llegaron a cumplir. Prueba de ello es la crisis de subsistencia que sufrió la población desde finales de los años treinta, que dio lugar a un éxodo rural. Asimismo, el asentamiento de españoles no fue exitoso, en la medida en que no se cubrió la oferta de tierras para colonizar y diversos colonos se vieron obligados a abandonar sus explotaciones.

Las razones que explican este balance son de diversa índole y tienen un impacto desigual. A nuestro entender, el éxito de la colonización dependía en gran medida de la política colonial y de la disponibilidad de medios humanos y materiales para llevarla a cabo. En cuanto al primer aspecto, probablemente debido al escaso interés que despertaron las opciones económicas del Marruecos precolonial en la Península, la planificación fue tardía. De hecho, comenzó en los años inmediatamente anteriores al protectorado. Buena parte de las resoluciones de los congresos africanistas dan cuenta de ello, pues son un síntoma de lo que se desconocía. Tuvo especial relevancia la petición de apertura de una granja experimental en la zona oriental (instalada en Melilla debido a los enfrentamientos entre el ejército español y la resistencia armada rifeña), que debía contribuir a la modernización agrícola. La memoria de José Vicente Arche de 1910, realizada sobre el terreno, reveló una actividad agrícola rudimentaria y la necesidad, a su 
parecer, de una transformación del sector en términos capitalistas, con la ayuda de la colonización agrícola.

La acción colonial de los primeros años fue lenta. Se legisló a favor de gestionar la explotación de bienes inalienables del Majzén (el resto no) y se comenzaron a explotar diversas propiedades. La colonización oficial se puso en marcha, aunque el plan que desarrollaba su actividad no se aprobó hasta 1923. Estaba inspirado en el informe de 1918 de Arrué, y al mismo tiempo reflejaba algunas de las características de la JCCRI metropolitana. Si las colonias agrícolas españolas buscaban dar solución (sin éxito) al acceso a la propiedad a familias que dispusieran de pequeños capitales, en las del norte de Marruecos se trataba de dar alternativas a la especulación inmobiliaria a un perfil de campesinos también con poca liquidez. Este perfil marcó un modelo de pequeña colonización, siendo la mayor parte de las parcelas, a priori, asequibles para colonos menos adinerados. No obstante, aquellos que tuvieran más disponibilidad de capitales (incluidas las empresas) se podían acoger a la gran colonización. A pesar de su carácter excepcional ocupó la mayor parte de la superficie repartida.

En estos primeros años la acción colonial fue lenta por la escasa planificación y desarrollo de las políticas, pero también por la campaña militar, que a partir de los años veinte se recrudeció y detuvo gran parte de la actividad, cuando la inseguridad creció en gran medida. Los alrededores de Tetuán y la zona atlántica, bajo control del ejército español tempranamente, garantizaron los primeros ensayos. Pero la labor militar copaba la mayor parte de las partidas presupuestarias, dejando en un segundo plano la civil. Así, con el fin de la guerra las autoridades coloniales depositaron sus esperanzas en un aumento de la colonización gracias al control del territorio. Y así fue en los primeros años de la nueva etapa de paz y prosperidad anunciada en la prensa. Pero los problemas financieros de los años treinta afectaron al presupuesto del protectorado, que dependía de la metrópoli. Ciertamente, el reparto de tierras se estancó de nuevo, lo cual fue aprovechado por la DAI para hacerse con el control de la colonización, pero su gestión no mejoró las cifras. Los problemas económicos de los años treinta no se detuvieron en los cuarenta, cuando el régimen franquista pasó por serias dificultades. De esta manera, aunque comprometida por circunstancias en principio ajenas a la actividad agrícola, la colonización oficial fue poco eficaz, porque no se logró un mayor reparto de tierras. También por los continuos problemas presupuestarios que sufrió. En este sentido los trabajos de acondicionamiento de tierras por parte de la Administración fueron escasos.

La llegada de colonos fue especialmente importante, como decíamos, en los primeros años, atraídos por unas condiciones que prometían tierras y apoyo institucional. Pero los sucesos de Annual conllevaron problemas de seguridad y el respaldo material de la 
Administración española se redujo. Si bien en los años treinta las autoridades españolas «recompensaron» a quienes iniciaron las primeras explotaciones oficiales con el acceso a la propiedad de sus parcelas, no es menos cierto que una buena parte de los colonos pasaron por serias dificultades y hubo abandonos de lotes. Incluso varios fueron represaliados a partir de 1936. Ante esta situación tan delicada, la demanda de tierras descendió y no se recuperó posteriormente, lo que dejó un balance negativo, pues su contribución a la modernización agrícola marroquí fue muy escasa.

\section{AGRADECIMIENTOS}

Este artículo se inscribe dentro del proyecto HAR2015-68183-P del Ministerio de de Economía. Quiero agradecer especialmente la revisión crítica del presente trabajo a los evaluadores anónimos de Historia Agraria. Sus indicaciones, sin duda, han mejorado notablemente el texto. Asimismo, me gustaría agradecer al profesor Eloy Martín Corrales las sugerencias que hizo en su día y al seminario del GRIMSE-UPF, que me brindó la oportunidad de presentar una primera versión de esta investigación, y cuyas discusiones contribuyeron también en gran manera a mejorarla.

\section{REFERENCIAS}

Ageron, C. R. (1979). Histoire de l'Algérie contemporaine. II: De l'insurrection de 1871 au déclenchement de la guerre de libération (1954). Paris: Presses universitaires de France.

AlDRICH, R. (1996). Greater France: A History of French Overseas Expansion. Basingstoke: Macmillan.

ANDERSON, L. (1987). The State and Social Transformation in Tunisia and Libya 18301980. Princetown: Princeton University Press.

ARCHE, J. V. (1910). Memoria acerca del estado actual de la agricultura en el Rif, y reformas posibles e inmediatas que conviene implantar. Madrid: Impr. de Sucesores de M. Minuesa de los Ríos.

Aziza, M. (2003). La sociedad rifeña frente al Protectorado español de Marruecos (19121956). Barcelona: Bellaterra.

Belguendouz, A. (1978). La colonisation agraire au Maroc et ses méthodes de pénétration. Revue juridique politique et économique du Maroc, (4), 115-151.

BIDwell, R. (1973). Morocco under Colonial Rule: French Administration of Tribal Areas, 1912-1956. London: Frank Cass. 
Bouche, D. (1991). Histoire de la colonisation française. II: Flux et reflux (1815-1962). Paris: Fayard.

Bravo, A. (2000). Arquitectura y urbanismo español en el norte de Marruecos. Sevilla: Junta de Andalucía.

BRULÉ, J.C. \& FontaIne, J. (1987). L'Algérie:Volontarisme étatique et aménagement du territoire. Beçanson: Université de Franche-Comté Tours.

CARTAÑÀ, J. (2000). Las Estaciones Agronómicas y las Granjas Experimentales como factor de innovación en la agricultura española contemporánea (1875-1920). Scripta Nova, 69 (16).

Centros Comerciales Hispano-Marroquíes (1909). Tercer Congreso Africanista. Barcelona: España en África.

Centros Comerciales Hispano-Marroquíes (1910). Cuarto Congreso Africanista. Barcelona: España en África.

Centros Comerciales Hispano-Marroquíes (1922). Los Centros Comerciales HispanoMarroquies y el Problema de Marruecos: La elocuencia de un inventario (De 1904 a 1921). Madrid: España en África.

Delaunay, J. M. (2010). Méfiance cordiale: Les relations franco-espagnoles de la fin du XIXème siècle à la Première Guerre Mondiale. 2: Les relations coloniales. Paris: Harmat$\tan$.

DíAz Morlán, P. (2015). Empresarios, militares y politicos: La Compañia Española de Minas del Rif (1907-1967). Madrid: Marcial Pons.

Domínguez Rodríguez, R. (2017). Políticas agrícolas en el protectorado español de Marruecos. Málaga: Universidad de Málaga.

El Abdellaoui, M. \& ChiKhi, N. (1997). El regadío y las transformaciones agrarias en el Rif. En J. A. GonZÁlez AlCANTUd et al., Transformaciones agrarias y cultura material en Andalucía oriental y norte de Marruecos (pp. 253-282). Granada: Diputación Provincial de Granada.

Falgueras, I. (1909). Estudios sobre sociología y derecho de Marruecos. Madrid: Hijos de Reus.

FERNÁNDEZ PRIETO, L. (2007). El apagón tecnológico del franquismo: Estado e innovación en la agricultura española del siglo XX. Valencia:Tirant lo Blanch.

Fleming, S. E. (1998). Spanish Morocco and the Second Republic: Consistency in Colonial Policy? Mediterranean Historical Review, 13 (1-2), 80-98.

FONT DE MORA, R. (1928). La colonización agrícola en la zona occidental del Protectorado español en Marruecos. Madrid: Ministerio de Fomento.

García Figueras, T. (1957). España y su protectorado en Marruecos (1912-1956). Madrid: Consejo Superior de Investigaciones Cientificas.

GozÁlvez PÉREZ, V. (1993-1994). Notas sobre la colonización agrícola en el Protectorado de España en Marruecos. Sharq Al-Andalus, (10-11), 423-452. 
HART, D. M. (1997). Estructuras tribales precoloniales en Marruecos bereber, 1860-1933: Una reconstrucción etnográfica en perspectiva histórica. Granada: Universidad de Granada.

JORDI, J.-J. (1986). Espagnol en Oranie: Histoire d'une migration, 1830-1914. Montpellier: Africa nostra.

LiAuZu, C. (1996). Histoire des migrations en Méditerranée occidentale. Bruxelles: Complexe.

López Morell, M. A. (2005). La casa Rothschild en España (1812-1941). Madrid: Marcial Pons.

Madariaga, M. R. (2005). En el barranco del lobo: Las guerras de Marruecos. Madrid: Alianza.

MADARIAGA, M. R. (2008). España y el Rif, crónica de una historia casi olvidada. Melilla: UNED.

Madariaga, M. R. (2013). Marruecos, ese gran desconocido: Breve historia del protectorado español. Madrid: Alianza.

MARCHÁN, J. (2011). Costa, los congresos africanistas y la colonización agrícola en Marruecos. En F. J. MartíneZ ANTONio \& I. GonZÁlez GonZÁlez (Eds.), Regenerar España y Marruecos: Ciencia y educación en las relaciones hispano-marroquíes a finales del siglo XIX (pp. 465-490). Madrid: Consejo Superior de Investigaciones Científicas.

MARChán, J. (2014). La colonización agrícola en el protectorado español de Marruecos (1912-1956): Una esperanza frustrada. Tesis doctoral. Barcelona: Universitat Pompeu Fabra.

MARCHÁN, J. (2015). Las instituciones agrarias del protectorado español en el norte de Marruecos y los primeros pasos de la colonización agrícola. En P. FolguerA et al. (Eds.), Pensar con la historia desde el siglo XXI: Actas del XII Congreso de la Asociación de Historia Contemporánea (pp. 2515-2530). Madrid: Universidad Autónoma de Madrid.

MARín, M. (2015). Testigos coloniales: Españoles en Marruecos (1860-1956). Barcelona: Bellaterra.

MARINA, J. F. (1942). Orientación sobre algunos problemas de la propiedad en Marruecos: Colección de artículos publicados en la prensa marroquí. Valladolid: Impr. Allén.

MARTíN, E. (2002a). La imagen del magrebi en España: Una perspectiva histórica, siglos $X V I-X X$. Barcelona: Bellaterra.

MARTín, E. (2002b). Represión contra cristianos, moros y judíos en la guerra civil en el protectorado español de Marruecos, Ceuta y Melilla. En F. Rodríguez Mediano \& H. DE FELIPE (Eds.), El Protectorado español en Marruecos: Gestión colonial e identidades (pp. 113-138). Madrid: Consejo Superior de Investigaciones Científicas.

MARTíN, E. (2008). La marroquinización de una ciudad colonial española: Alhucemas, 1925-1956. En J. A. GonZÁlez AlCANTUd (Ed.), La ciudad magrebi en tiempos coloniales: Invención, conquista y transformación (pp. 201-231). Barcelona: Anthropos. 
MARTín, E. (2013). El movimiento obrero en el protectorado español de Marruecos (1931-1936). EnVV. AA., Ceuta y el norte de África entre dos dictaduras (1923-1945) (pp. 177-205). Ceuta: Instituto de Estudios Ceutíes.

Mateo, J. L. (2003). La «hermandad» hispano-marroqui: Política y religión bajo el Protectorado español en Marruecos (1912-1956). Barcelona: Bellaterra.

Michel, N. (1997). Une économie de subsistances: Le Maroc précolonial. Le Caire: Institut Français d'Archéologie Orientale.

MiQuÉLEZ, C. (1907). Notas de derecho musulmán o rasgos del Charaa. Melilla: Impr. El Telegrama del Rif.

MogA, V. (2007). Introducción: El Rif en el imaginario colonial español:Víctor Ruiz Albéniz. En V. Ruzz AlbÉNIZ, España en el Rif (1908-1921) (pp. XI-XXXI). Melilla: Consejería de Cultura y Festejos de la Ciudad de Melilla.

MoisAND, J. (2015). Migrant-e-s entre deux empires: Journaliers agricoles espagnols à Cuba et en Algérie dans les années 1880-1890. Revue d'histoire du XIX siècle, (51), 89-106.

Molero, J. (2003). Militares, «moros»y mosquitos: El paludismo en el protectorado español en Marruecos (1912-1956). En E. Rodríguez, R. BALlester, E. Perdiguero, R. M. MEDINA \& J. Molero, La acción médico-social contra el paludismo en la España metropolitana y colonial del siglo XX (pp. 323-380), Madrid: Consejo Superior de Investigaciones Científicas.

MORLA, V. DE (1947). España en Marruecos: La obra social. Madrid: Instituto de Estudios Africanos.

Nerín, G. (2005). La guerra que vino de África. Barcelona: Crítica.

Notas varias sobre bienes Habus (S.f.). S.1.: s.n. [Copia mecanografiada, Biblioteca Nacional de España].

Paniagua, A. (1992). Repercusiones sociodemográficas de la política de colonización durante el siglo XIX y primer tercio del XX. Madrid: Ministerio de Agricultura, Pesca y Alimentación.

Pan-Montojo, J. (1995). La administración agraria en España, 1847-1907. Historia Agraria, (10), 67-88.

Pennell, C. R. (2000). Morocco since 1830: A history. London: Hurst.

Perkins, K. J. (2010). Historia del Túnez moderno. Madrid: Akal.

Pervillé, G. (2012). La France en Algérie, 1830-1954. Paris:Vendémiaire.

PONCET, J. (1962). La colonisation et l'agriculture européennes en Tunisie depuis 1881: Étude de géographie historique et économique. Paris: Mouton.

Rivet, D. (1999). Le Maroc de Lyautey à MohammedV: Le double visage du protectorat. Paris: Denoël.

Rodríguez Esteban, J. A. (1996). Geografía y colonialismo: La Sociedad Geográfica de Madrid (1876-1936). Madrid: Universidad Autónoma de Madrid. 
RUIZ AlbÉNIz, V. (1930). Monografía sobre colonización rural en Marruecos español. Madrid: Impr. Sáez Hermanos.

SAlahdine, M. (1986). Maroc: Tribus, makhzen et colons: Essai d'histoire économique et sociale. Paris: Harmattan.

Swearingen, W. D. (1987). Moroccan Mirages:Agrarian Dreams and Deceptions, 19121986. Princeton: Princeton University Press.

TORRE, R. DE LA (2007). Bajo el signo de la redistribución colonial: La política exterior española entre 1895 y 1907. Historia Contemporánea, (34), 65-92.

TORREJÓN, A. DE, ARIAS, P. \& ARRUÉ, A. (1923). Estudios e informe relativos a la colonización agrícola de la zona de protectorado de España en Marruecos. Madrid: Impr. Helénica.

TORREJÓN, A. DE (1939). Características agrícolas, labor de colonización realizada, causas que impiden el desarrollo agrícola y bases para un futuro plan de colonización en la Zona de Protectorado de España en Marruecos. Ceuta: Delegación de Fomento, Servicio Agronómico.

VILAR, J. B. (1985). Los orígenes de la inmigración laboral marroquí en la Argelia francesa: Los rifeños en la Oranie (1855-1863). Cuadernos de Historia Moderna y Contemporánea, (6), 117-146.

VILAR, J. B. (1989). Los españoles en la Argelia francesa (1830-1914). Madrid: Centro de Estudios Históricos.

VILAR, J. B. \& VILAR, M. J. (1999). La emigración española al norte de África (1830-1999). Madrid: Arco/Libros.

VILlanova, J.L. (2003): La organización política, administrativa y territorial del protectorado español en Marruecos (1912-1956). El papel de las Intervenciones. Girona: Universitat de Girona.

Villanova, J. L. (2004). El Protectorado de España en Marruecos: Organización política $y$ territorial. Barcelona: Bellaterra.

Villanova, J. L. (2006). Los interventores: La piedra angular del Protectorado español en Marruecos. Barcelona: Bellaterra.

YAZIDI, B. (2005). La politique coloniale et le domaine de l'Etat en Tunisie. Sahar: Faculté des lettres de Manouba. 